\title{
O Ornitólogo e a Arapuca: Notas sobre a Palavra Cerzida e Grupo Escolar de Cacaso
}

Débora Racy Soares (UNICAMP)

RESUMO: Quando convocado a se definir como poeta, Cacaso (1944-1987) teria dito que era poeta que escuta. Tal atitude poética certamente resulta em um tipo de poesia aberta à experiência alheia. Até aí parece não haver muita novidade, pois a disponibilidade para ouvir combina bem com uma outra, a de "espírito", que Cacaso acreditava ser mesmo imprescindível à criação artística. Mas se ambas as disponibilidades podem se confundir, em determinado momento, uma nem sempre implica a outra. Em outras palavras: nem sempre quem ouve consente. E se quem cala, sente, Cacaso - apesar de, aparentemente, "não querer prosa" - apostava na força vital do diálogo para reavivar o monólogo oficial. Nossa proposta é escutar sua trajetória poética, dando ouvidos a um modo muito peculiar de fazer versos.

PALAVRAS-CHAVE: Cacaso; criação artística, experiência.

ABSTRACT: When summoned to define himself as poet, Cacaso (1944-1987) would have said that he was a poet who listened. Such poetical attitude certainly results in a type of a poetry open to the other people's experience. Until that, it seems there is nothing new, therefore the availability to hear combines well with one another, that of "spirit", which Cacaso exactly believed to be essential to the artistic creation. But if both availabilities can be confused, in a specific moment, one does not always imply to the other one. Or not always one who listens assents to it. And if that who is silent, feel, Cacaso - although, apparently, "not wanting to chat" - bet in the vital force of the dialogue to revive the official monologue. Our proposal is to listen to its poetical trajectory, listening to a very peculiar way of making verses.

KEYWORDS: Cacaso; artistic creation; experience.

\section{INTRODUÇÃO}

Antônio Carlos de Brito, mais conhecido por Cacaso no meio intelectual e literário dos anos setenta, além de crítico e teórico de sua geração - a dos "marginais do mimeógrafo" - também foi poeta. O fato merece atenção, já que suas poesias parecem 
ter, até então, passado despercebidas das lentes dos críticos literários. Salvo, é preciso dizer, raras e localizadas exceções que, apesar de mencioná-lo, não detêm o olhar na especificidade de seus versos. É interessante perceber que a produção poética de Cacaso tem, recentemente, despertado a atenção de alguns estudiosos, desejosos em ressuscitálo. Talvez não tenha sido caso de morte. Ou se foi, a "indesejada da gente" parece ter atingido somente a poesia. Isso porque se o poeta, morto de fato em 1987, precisa ser relembrado em matéria de poesia, no quesito música, não lhe faltam ouvidos. Sem muito esforço e, com um pouco de sorte, ainda é possível sintonizar "Lero-Lero" em algumas FMs do país. Com letra de Cacaso e música de Edu Lobo, com quem iniciou uma produtiva parceria em 1976, o hit que caiu no gosto do público seria posteriormente regravado por vários artistas, como os do grupo Garganta Profunda. Se a quadrinha "Sou brasileiro/de estatura mediana/ gosto muito de fulana/ mas sicrana é quem me quer" tornou-se familiar, não é preciso relembrar uma de suas principais composições, "Dentro de Mim Mora um Anjo", interpretada magistralmente, em 1975, por sua outra parceira: Sueli Costa. A música virou trilha sonora da novela "Bravo", da Rede Globo, tendo sido, posteriormente, incluída no repertório de Fafá de Belém. Para os que na época não tinham nascido ou usavam fraldas, é possível escutar "Dentro de mim..." em show recente de Lucinha Lins.

Diante destas observações, somos tentados a recorrer aos questionamentos de outro poeta, também mineiro, como Cacaso, porém de Itabira, não de Uberaba. Quem “entortou” nosso ouvido ou a poesia? A pergunta é pertinente, já que a produção do letrista e do poeta corria pari passu. Nesse sentido, desconfiamos de que, a partir de um determinado momento, o trânsito entre poesia e letra de música passou a ser intenso. Apesar de Cacaso acreditar que poesia e música eram dois "negócios" completamente distintos, no percurso de suas composições percebemos como muito do que ali se encontra, já havia se esboçado poeticamente. Versos inteiros descolam-se dos livros de poesia e são reaproveitados em forma de quadrinhas ou refrões musicais. Cacaso experimenta o som e o ritmo das palavras nas quebras e repetições de suas letras e poemas. A poesia parece, dessa forma, servir como celeiro para as letras de música. Talvez o inverso também seja pertinente, mas não importa muito entrar em discussões como as do "ovo-galinha". Vale mais perceber que Cacaco, em um primeiro momento, 
encarava as duas atividades de formas bem distintas e tinha expectativas diversas em relação a elas.

\section{O LETRISTA QUE ERA POETA}

No palpite de Helena Aragão, Cacaso parece ter ficado conhecido antes como poeta do que como letrista. Será? Vejamos. Seu primeiro livro de versos, A Palavra Cerzida, é de 1967. Mas por onde andava Cacaso antes de sua aparição no cenário literário brasileiro? Em 1962, com 18 anos, Cacaso acabara de compor "Carro de Boi" com Maurício Tapajós. Com esta música, gravada pelo grupo "Cariocas", ele demarcaria seu lugar no terreno musical da época. A canção ficou tão popular entre o pessoal do "Clube da Esquina" que Milton Nascimento resolveu regravá-la em seu disco "Geraes", de 1976. É nesse período que sua atividade musical deslancha, ao lado de parceiros como Nelson Ângelo e Novelli. Daí para frente, a produção musical de Cacaso se intensifica, enquanto sua produção poética decresce. Ou como ele diz, em 1980: "tem uns dois anos que eu não consigo fazer um poema, a verdade é essa. Só sei fazer letra de música" (1981: 08). Não sem certa tristeza, Cacaso reconhece que, desde seu livro de 1978 - Na Corda Bamba - sua poesia "foi ficando pequena, foi diminuindo o tamanho, e sumiu" (1981: 08). Seu próximo livro, Mar de Mineiro que sairia em 1982, é um livro de poemas e canções. Mais canções (75) do que poemas (44). Dedicado aos parceiros musicais Nelson Ângelo e Novelli, Mar de Mineiro baliza a definitiva passagem de Cacaso da marginalidade poética (esgotada em sua essência com as sinalizações de abertura política) e a sua consagração no mercado fonográfico. É a partir de 1976, como lembra Nelson Ângelo, que Cacaso começa a intensificar sua produção musical. Sua idéia era "compor bastante" para quando "as pessoas perceberem", já “estar com um projeto pronto" (2000: 110). Aliás, é com Nelson que Cacaso compõe mais de oitenta canções, muitas das quais escritas quando se encontravam para produzir. Era na casa de Cacaso que, aos goles de pinga mineira, os parceiros admiravam o mar de Copacabana e lamentavam a inexistência de mar em Minas. Dois mineiros (Nelson nasceu em Belo Horizonte), convertidos à maresia, sofriam de um mal maior: saudades Gerais. Em 2002, Nelson Ângelo lançou o CD Mar de Mineiro, com 13 músicas oriundas de sua parceria com Cacaso. No encarte que acompanha o CD, Nelson recorda quanto ambos acalentavam, desde os anos setenta, o sonho de gravarem juntos. 
Segundo Cacaso, a música poderia lhe garantir projeção nacional e com ela teria "chance de ficar conhecido no Brasil inteiro". No que tange à poesia, Cacaso acreditava que mesmo que ela desse certo, poderia deixá-lo "confinado ali na esquina". E acrescenta que sua "experiência com poesia" era "num setor minúsculo" (2000: 109). À medida que Cacaso foi percebendo sua musicalidade e sua capacidade de "inventar palavras sobre melodias", passou a não mais dissociar música e poesia (2000: 113). Sua mudança de opinião provavelmente foi condicionada por seus estudos em "música, modernismo, cultura brasileira" (2000: 104). A leitura de Mário de Andrade parece ter sido fundamental neste momento. Além de ter influenciado Cacaso em sua busca de sonoridades, parece ter-lhe assegurado também o "direito à pesquisa" e "à liberdade de inovar", como condições determinantes de sua atividade criativa (2000: 107). Para ele, após Vinícius de Moraes, a música e a poesia brasileira estariam "misturadas para sempre" (2000: 109). Aliás, Cacaso chegou até mesmo a ser considerado o "legítimo herdeiro" do "poetinha" quando começou a fazer sucesso no meio musical (Hollanda 2000: 240).

Durante a infância, uma das "brincadeiras prediletas" de Cacaso era colocar "mentalmente uma letra nova nas melodias que ouvia no rádio". Foi através da música, diz ele, que aconteceu seu "primeiro contato com o texto" (2002: 109). Aliás, quando era pequeno, cantor de rádio era o que almejava ser no futuro. O "poeta que escuta", como Cacaso se autodenominava, era desafinado. "Cantava fora do tom o verso que acabara de compor" (Landim, 2000: 113). E era entendido em passarinhos.... Ainda está por ser feito um trabalho que se dedique exclusivamente às letras de música de Cacaso.

\section{O POETA QUE ERA LETRISTA}

A estréia poética de Cacaso, em 1967, com A Palavra Cerzida, embora tenha sido louvada pelo crítico José Guilherme Merquior, em nota introdutória do livro, revelou-se uma "experiência muito frustrante" para o autor. Cacaso que, naquela ocasião, assinava Antônio Carlos de Brito, diz ter ficado "sete anos sem conseguir escrever" após a publicação deste primeiro livro (1981: 06). Esse livro que saiu sob o aval da editora José Álvaro, nunca foi, na opinião de Cacaso, "lido" ou "comprado por ninguém" (1981: 06). Como ele foi "uma coisa tão inexistente na (sua) vida" e lhe 
causou a "sensação de ser editado, e não ser", Cacaso foi levado a desconfiar de suas possibilidades como poeta. Em sua opinião, a recepção quase nula de $A$ Palavra Cerzida deveu-se ao fato de ter escrito "uma poesia muito complicada, muito intelectualizada, com pretensão um pouco filosófica” (1981: 06). Motivado pela pretensa baixa receptividade de sua obra, Cacaso procurava justificar sua "complicação" poética dizendo que na época era estudante de Filosofia (na UFRJ). Em outros momentos, chega até a afirmar que o livro de 1967 é "um livro de estudante de Filosofia" porque "tem o ser e o nada". "Mais construído" e "menos voltado para a vida" é como o jovem poeta considera seu livro inicial (Pereira1981: 164). Será com Grupo Escolar (1974), seu segundo livro, que Cacaso inaugurará sua fase "marginal do mimeógrafo". Neste novo momento de sua produção poética as motivações para escrever são outras e refletem a dicção mais espontânea - que não se dá sem grande esforço construtivo - e aparentemente menos literária do autor. Cacaso diz ter sido encorajado a "volt(ar) a arriscar" escrever poesia, estimulado por Ana Luísa Escorel (1974: s/p). Ele havia cooperado com sua tese para a Escola Superior de Desenho Industrial, escrevendo poemas para ilustrar determinadas imagens. Portanto, a maioria dos poemas de Grupo Escolar só ganha força se lida no diálogo com o suporte imagético. É lamentável que a recente edição da coletânea das obras poéticas de Cacaso (Lero-Lero, 7 Letras, Cosac \& Naify, 2002) tenha suprimido todas as fotos e desenhos dos livros originais. As fotos da edição original de Grupo Escolar são de Maria Elizabeth Ribeiro Carneiro, a Betinha (assim chamada pelo poeta), que ao lado de Ana Luísa, autora da capa, são consideradas "co-autoras” do livro (Brito, 1974: s/p).

Grupo Escolar é o primeiro livro de Cacaso produzido alternativamente. Ele integrou a Coleção Frenesi do Rio de Janeiro e, para ser publicado, contou com o apoio financeiro da Mapa Filmes Ltda., através de Zelito Viana. A idéia da publicação, de forma independente, através de Coleções de poesia, fez parte da dinâmica de produção dos poetas conhecidos como "marginais dos anos 70". Ao tomar as rédeas do movimento marginal carioca, sendo um de seus principais teóricos, Cacaso encarava a "liderança" como sua "atividade mais séria", junto com a de "letrista da MPB" (2000: 102). 
Neste momento, a poesia passou a ser encarada de forma diferente. Se antes, em A Palavra Cerzida, a produção poética exigia uma "programação rígida", de Grupo Escolar em diante, ela passa a acontecer "a todo tempo" e "em qualquer lugar" (Pereira 1981: 164). A volta à poesia, diz Cacaso, acontece por "razões que não têm nada a ver com a literatura, razões muito mais de desabafo pessoal e de vontade de juntar umas pessoas, fazer planos e editar coleções de livros" (1981: 06). É nesse momento que Cacaso tem a "sensação de ser um autor de livros de poesias" (1981: 07). A divulgação e distribuição dos livros de poesia, feitas manualmente e em locais restritos, contribuíram para que Cacaso fosse reconhecido como poeta, ainda que "num circuito minúsculo". Certamente o poeta queria ser reconhecido e é difícil avaliar se a "fama" que o "deixava um pouco atrapalhado" decorria de sua incursão no universo poético ou musical (Schwarz 1988: 135). Se vale um palpite, talvez ele tenha mesmo ficado famoso fazendo letras, como acreditava. O que importa é que, se o empreendimento marginal o deixou descapitalizado, sua entrada no mercado fonográfico fez com que "ganhasse dinheiro com seu trabalho" (Schwarz 1988: 135). A essa altura, Cacaso reconhece que retomar o "hábito antigo" de escrever letras de música lhe garantiu a "profissionalização" que para o "poeta que faz livros é um negócio quase impensável" (1981: 07). Foi talvez, neste momento, que tenha acreditado que "sua vida de intelectual e artista seria mais livre compondo letras de música popular do que dando aulas na faculdade" (Schwarz 1988: 135). Daí a "qualificação profissional”, que viria através de sua defesa de tese na USP, ter "perdido todo o sentido" (Brito 1981: 07). A poesia, que agora é encarada de forma "descompromissada", assegura, como diz Cacaso, um bem que lhe é muito precioso: a "gratuidade da atividade criadora" (1981: 07).

\section{DO PÁSSARO INCUBADO AO GALO AMANHECIDO}

Se há alguma presença constante na obra poética de Cacaso, mais acentuadamente nas duas primeiras, A Palavra Cerzida e Grupo Escolar, é a imagem das aves. Elas surgem de várias formas, seja através de pássaros e andorinhas, galos e tico-ticos ou gaivotas e urubus. Se as aves figuram em diferentes metáforas poéticas, sua força alusiva só faz acentuar a densidade semântica dos versos de Cacaso.

"O pássaro incubado", poema de abertura de A Palavra Cerzida, introduz a voz de um poeta iniciante que busca um lugar para aninhar-se na moderna tradição poética. 
Seu canto, à procura de afinação, constrói-se cantando. Sua entoação, já em muito singular, conquistará força em seus livros posteriores. Como pássaro arisco, o poeta ainda "é aurora que não se arrisca" (1967: 23). É “pássaro" engaiolado, "não é dono de onde mora", "nem mora onde é inquilino" (1967: 18). Qual seria o lugar do pássaro? Seus versos, formalmente bem acabados, ciscam na tradição poética do modernismo. Nesse primeiro momento, o diálogo com poetas como Murilo Mendes, João Cabral, Manuel Bandeira, Cecília Meireles e Bruno Tolentino sinaliza uma fase que é de formação e de maturação latentes. Tal como "pássaro incubado", o poeta choca sua poesia "inacabada", vestindo "roupa(s)" alheias (1967: 17). Se a apropriação de outras vozes, em certa medida, determina sua poesia, nesse sentido não há como fugir da “gaiola”, prisão necessária, que moldou suas primeiras penas. A passagem pela tradição poética modernista configura-se penosa, porém vital - o poeta "habita cada momento que existe dentro do cubo"- e sabe "ser duro" (1967:17). Será na dureza, na resistência à voz da tradição e, posteriormente da censura, que Cacaso alcançará seu canto mais vívido. Apesar de sua poesia ainda configurar-se ao lado de outros cantos, ela já se define na opção pelo "meio", pela multidão. Tal qual andorinha, o poeta não quer cantar pelas "arestas", sozinho. Acalenta a fuga, sonhando com a liberdade fora do "domínio" da gaiola tradicional que "lhe decepa as asas". Quando alçar vôo livre, estará no mundo, não como "geógrafo quase alheio", "encubado" e protegido, mas como "nervo exposto" (1967: 77) Nesse sentido, Cacaso afirma sua poética pelo negativo: talvez ainda não tenha muita certeza do que deseja, mas certamente conhece o que não quer. Embora a metáfora do pássaro engaiolado seja lugar-comum na literatura brasileira, é bom lembrar que em meados de 66/67 ainda havia possibilidade de liberdade de expressão entre os artistas. Se o golpe de 1964 "pegou o país em um momento de grande agitação cultural", o período mais complicado da ditadura militar ainda estava por vir (Brito, 1997: 103-104). O galo, como figura transgressora, também aparece neste livro. Destituído de sua função universal de anunciar o dia, o "galo amanhece" enquanto o dia “canta no terreiro" (1967: 23). O estranhamento poético, suscitado pela inversão da ordem do mundo, anuncia uma poesia que se fará por constantes deslocamentos. Pelo canto do galo fala o poeta "em tempo de notícia": "sou mapa e não me desvendo" (1967: 33). O "geógrafo" convertido em mapa, precisa decifrar-se, aprender geografia. Em outras palavras: se o aprendizado poético é também existencial, a poesia capta um 
momento único de ser e estar no mundo. Momento talvez "inútil", diz o poeta ressentido com a passagem do tempo em "Anulação". Através do tempo, o poeta se reinventa: "Me invento na laje/ no corte/ e na palavra. Inútil: estou sempre recomeçando" (1967: 39). Recomeçar parece ser palavra de ordem em Cacaso. E será de outro lugar que ele voltará à cena poética em seu livro seguinte, Grupo Escolar.

\section{A GAIVOTA E O TICO-TICO}

O "resgat(e) do mundo posto à margem", anunciado em "Alegorias", último poema de A Palavra Cerzida, parece sinalizar a necessária "transform(ação)" do poeta “em verbo" (1967: 167). O tom altivo do primeiro livro cede lugar, em Grupo Escolar, ao coloquial, marcado pela ironia corrosiva - praticamente inexistente no livro de 1967 - e a uma poesia mais comprometida com as vivências cotidianas. Na foto de um cartaz que abre o livro de 1974, lemos: "divirta-se à vontade". O livro, dedicado ao filho Pedro, que nascera em 1971, introduz uma novidade. Além do contínuo aprendizado poético - vejam que o poeta volta aos bancos escolares - assistimos à sua iniciação paterna. Ambos os fatos organizam a estrutura interna do livro que é divido em quatro partes-"lições"- correspondentes às quatro séries do antigo grupo - intercaladas por nove fotos de seu filho (serão os nove meses de gestação?). Além das fotos de Pedro, encontramos também fotos de cenas de rua que dizem bastante sobre o Brasil da época. Não é com certa tristeza que observamos que muitas dessas fotos continuam atuais, assim como algumas situações precárias denunciadas pela poesia, como as de "Logias e Analogias" (No Brasil a medicina vai bem/ mas o doente ainda vai mal...). Em bem poucos momentos, parece haver certa queda de voltagem literária dos versos que acabam virando uma espécie de veículo de denúncia das mazelas sociais. Mas quase sempre Cacaso acerta na escolha de procedimentos literários que têm grande rendimento poético, como a alegoria, para dizer sobre um Brasil à margem, que escapa dos binóculos oficiais. Como dissemos, o aprendizado poético continua, o que fica claro através dos cinco poemas iniciais, "Cartilha(s)", cada um correspondendo a uma vogal. O "poema anfíbio" continua construindo-se no embate com a tradição. Porém, agora a voz do outro soa menos conformada e mais deturpada. Em alguns poemas, atiça-se a paródia contra a paródia, e o mapa, agora "mundi” e desvendado, “viaja/ entre suspiros de amor". Uma "gaivota bissexta" cruza os ares do poema, e como o poeta, "desova a tarde" que é poesia (1974: s/p). O pássaro incubado de então transforma-se em gaivota. 
Em liberdade, alça vôos mais altos e pode pôr seus ovos. É sintomático observar como o pássaro manteve-se fiel ao apelo do galo. O recrudescimento da censura, decorrente do AI-5 em dezembro de 1968, se amedronta metaforicamente o canto do pássaro, por outro lado, o fortalece. Se é premente voar mais alto, como as gaivotas, e "já sem resistência resist(ir)", também é urgente assegurar a estratégia do tico-tico: dele ninguém rouba o fubá. Ou como diz a letra de "Lero-Lero": "Diz um ditado/ natural da minha terra/ bom cabrito é o que mais berra/ onde canta o sabiá/ desacredito/ no azar da minha sina/ tico-tico de rapina/ ninguém leva o meu fubá" (1982: 169). De rapina são mesmo algumas poesias de Cacaso que aparecem neste Grupo Escolar. É através da estratégia de apropriação da voz alheia, atualizada em tempo de "Brasil político", como diz Ferreira Gullar, que as poesias ganham fôlego maior (de cabrito?). Drummond, Gonçalves Dias, Oswald de Andrade se comparecem em raros momentos do segundo livro, surgem não como vozes impositivas de certa tradição poética, mas para fortalecer a autoria de um tico-tico que ousou desafinar o canto coletivo. Só mesmo sendo especialista em aves para fugir de tantas e tamanhas arapucas...

\section{OBRAS CITADAS}

BRITO, Antônio Carlos de. 1967. A Palavra Cerzida. Rio de Janeiro: José Álvaro. 1974. Grupo Escolar. Rio de Janeiro: Frenesi.

1981. Coleção Remate de Males 2 - Rebate de Pares (revista). Org. Berta Waldman e Iumna Maria Simon. Instituto de Estudos da Linguagem, UNICAMP, Campinas. 6-9. 1982. Mar de Mineiro. Rio de Janeiro.

1997. Não Quero Prosa. Org. e Seleção Vilma Arêas. Campinas: Editora da UNICAMP, Rio de Janeiro: Editora da UFRJ, 1997.

2000. Revista Inimigo Rumor: Especial Cacaso. Rio de Janeiro, maio. ISSN: $1415-9767$.

HOLLANDA, Heloisa Buarque de. 2000. Vida de Artista. In: Gaspari, E., Hollanda, H. B., Ventura, Z.Cultura em Trânsito: da Repressão à Abertura. Rio de Janeiro: Aeroplano. 239-242.

LANDIM, Pedro. 2000. Carinho Eterno. In: Revista Inimigo Rumor: Especial Cacaso. Rio de Janeiro, maio. 113-114. ISSN: 1415-9767. 
PEREIRA, Carlos Alberto Messeder. 1981. Retrato de Época: Poesia Marginal Anos 70. Rio de Janeiro: FUNARTE.

SCHWARZ, Roberto. 1998. O Poeta dos Outros. Revista Novos Estudos CEBRAP, no. 22. São Paulo, outubro. 135-156. 